\title{
Analysis of the regenerative braking process for the urban traffic conditions
}

In a regular drive system, with an internal combustion engine, vehicle braking is connected with the unproductive dissipation of kinetic and potential energy accumulated in the mass of the vehicle into the environment. This energy can constitute up to $70 \%$ of the energy used to drive a vehicle under urban conditions. Its recovery and reuse is one of the basic advantages of hybrid and electric vehicles. Modern traffic management systems as well as navigation systems should take into account the possibility of the energy recovery in the process of regenerative braking. For this purpose, a model of a regenerative braking process may be helpful, which on the one hand will enable to provide information on how traffic conditions will affect the amount of energy dissipated (wasted) into the atmosphere, on the other hand will help to optimize the route of vehicles with regenerative braking systems. This work contains an analysis of the process of the regenerative braking for the urban traffic conditions registered in Gdańsk. A model was also presented that allows calculating the amount of energy available from the braking process depending on the proposed variables characterizing the vehicle traffic conditions.

Key words: regenerative braking, real traffic conditions, hybrid and electric vehicles, energy consumption, route planning

\section{Introduction}

The increasing traffic intensity in cities and the rapidly growing population of the large agglomerations causes a continuous increase in $\mathrm{CO}_{2}$ emissions and harmful compounds from the combustion of conventional fuels [4]. A number of technical solutions $[17,19,20]$ and infrastructure solutions are implemented to reduce the impact of the automotive transport on the environment while maintaining or even increasing the flow of traffic [7, 13]. One of the most important factor actively influencing the working conditions of vehicle drive system and indirectly also the emission of toxic compounds, is the proper planning of the journey. Currently, there are a number of mobile applications that are updated basing on the current traffic conditions $[6,18]$, that enable shortening the travel time at the declared start and end points of the journey. However, it should be noted that while in the case of classic propulsion systems used in urban conditions, minimal traffic congestion problems transverse into high efficiency of the engine [1], in the case of alternative drive systems [15] such a relationship may no longer be unambiguous.

Using hybrid and electric drive systems, it is possible to use regenerative braking energy $[3,5]$, which means that the fastest route, with a limited number of braking processes, will not always be the most energy-efficient way. The technical solutions developed in recent years, which use the recuperative braking energy, allow the conversion of mechanical energy into electricity with high efficiency, even for very high power $[8,16]$. The control strategies for hybrid and electric vehicles in the field of regenerative braking energy are relatively complex and depend strongly on the state of charge of the batteries [2]. However, as a rule, manufacturers of such vehicles are trying to use as much as possible the regenerative braking energy for charging batteries. Tests performed on Toyota C-HR in urban conditions [14] showed that, the share of energy recovery from regenerative braking is over $50 \%$ of all energy supplied to the battery while driving.
It is necessary to consider the possibility of regenerative braking when planning the route of such vehicles, which is not implemented with the use of today's car navigations.

For this purpose, a model of a regenerative braking process may be helpful, which on the one hand will enable to provide information on how traffic conditions will affect the amount of energy dissipated (wasted) into the atmosphere, on the other hand will help to optimize the route of vehicles with regenerative braking systems.

This work contains an analysis of the process of the regenerative braking for the urban traffic conditions registered in Gdańsk. A model was also presented that allows calculating the amount of energy available from the braking process depending on the proposed variables characterizing the vehicle traffic conditions. The model is evaluated using mean cycle parameters, which is crucial for storing data from real world traffic.

\section{Identification of the vehicle traffic conditions}

Vehicle operating conditions are identified in this work with the use of the specific energy consumption (SEC) that takes into account both an influence of external conditions and driver's style of driving [9, 11]. Factors mentioned above affect the amount of mechanical energy transmitted to the drive wheels, which is one of parameters constituting the specific energy consumption. Information on specific energy consumption for the considered road section can be directly used to calculate electricity consumption in the case of battery-powered vehicles. The value of parameter for assumed cycle duration may be calculated using the following equation:

$$
\mathrm{SEC}=\frac{\mathrm{E}}{\mathrm{m} \cdot \mathrm{L}}
$$

where: SEC - the specific energy consumption, E - the mechanical energy delivered by drive system to the wheels, $\mathrm{L}$ - the distance covered by the car, $\mathrm{m}$ - the gross vehicle mass.

Mechanical energy transmitted to the drive wheels may be calculated with the use of two methods. The first method 
requires measurement of torque of the engine and rotational speed as well as determining power transmission system efficiency:

$$
E=\int_{t=0}^{t=t_{c}}\left(k_{p} \cdot M \cdot \omega \cdot \eta_{t}\right) d t
$$

where: $M-$ engine torque, $t_{c}-$ time of the cycle, $\omega=2 \pi n-$ engine angular velocity, $\mathrm{n}-$ engine rotational speed, $\eta_{\mathrm{t}}-$ power transmission system efficiency, $\mathrm{k}_{\mathrm{p}}$ - positive traction force factor:

$$
\mathrm{k}_{\mathrm{p}}=\left\{\begin{array}{l}
1 \text { for powered wheels } \\
0 \text { for idlling or breaking }
\end{array}\right.
$$

In the second method the mechanical energy transmitted to the drive wheels can be calculated using the following equation:

$$
E=\int_{t=0}^{t=t_{c}}\left(k_{p} \cdot F_{t} \cdot V\right) d t
$$

where: $F_{t}$ - traction force, $V$ - vehicle velocity.

Alternatively for the data recorded at the uniform time step, mechanical energy transmitted to the drive wheels may be calculated using the following equation:

$$
\mathrm{E}=\Delta \mathrm{t} \cdot \sum_{\mathrm{i}=1}^{\mathrm{N}}\left(\mathrm{k}_{\mathrm{p}_{\mathrm{i}}} \cdot \mathrm{F}_{\mathrm{t}_{\mathrm{i}}} \cdot \mathrm{V}_{\mathrm{i}}\right)
$$

where: $\Delta \mathrm{t}$ - time step.

Concerning usage of electric motor supporting conventional drive system the regenerative braking energy must be taken into consideration. The regenerative braking energy for the registered traffic conditions can be calculated using following equation:

$$
\mathrm{E}_{\mathrm{reg}}=\Delta \mathrm{t} \cdot \sum_{\mathrm{i}=1}^{\mathrm{N}}\left(\mathrm{k}_{\mathrm{reg}_{\mathrm{i}}} \cdot \mathrm{F}_{\mathrm{t}_{\mathrm{i}}} \cdot \mathrm{V}_{\mathrm{i}}\right)
$$

where: $\mathrm{k}_{\mathrm{reg}}$ - negative traction force factor:

$$
\mathrm{k}_{\mathrm{reg}}=\left\{\begin{array}{l}
-1 \text { for idlling or breaking } \\
0 \text { for powered wheels }
\end{array}\right.
$$

Regenerative braking specific energy (RBSE) for the covered distance can be calculated using following equation:

$$
\mathrm{RBSE}=\frac{\mathrm{E}_{\mathrm{reg}}}{\mathrm{m} \cdot \mathrm{L}}
$$

Calculation of the absolute electric energy consumed from battery by drive system in pure electrical mode can be made using the following equation:

$$
\mathrm{E}_{\text {battery }}=\mathrm{m} \cdot \mathrm{L} \cdot\left(\mathrm{SEC} \cdot \frac{1}{\eta_{\mathrm{el}}}-\mathrm{RBSE} \cdot \eta_{\mathrm{reg}}\right)
$$

where: $\eta_{\mathrm{el}}$ - efficiency of electric drive system including: battery, inverter, motor and transmission. $\eta_{\text {reg }}-$ efficiency of regenerative braking system including: transmission, generator, inverter, battery, or electric energy consumption:

$$
\mathrm{EEC}=\mathrm{SEC} \cdot \frac{1}{\eta_{\mathrm{el}}}-\mathrm{RBSE} \cdot \eta_{\mathrm{reg}}
$$

For further analysis purposes it will be also used the share of the regenerative braking specific energy (in relation to the specific energy consumption).

\section{The influence of the traffic conditions on the regenerative braking specific energy}

To identify the influence of the traffic conditions on the regenerative braking specific energy the road tests in town Gdansk (app. 1 million inhabitants), in normal urban traffic, were performed. In the tests a passenger car (petrol powered engine, mass app. $1350 \mathrm{~kg}$ ) was used, equipped with GPS (Global Positioning System) system and on-board CAN-Bus (Controller Area Network) registration system for measuring of operating drive system parameters (Fig. 1). The tests comprise drives during working days and were performed at different time intervals throughout the day and night. The height measurements provided by GPS system have been modified using a phenomenological correction [10]. This correction relayed on excluding the height data that gave the road inclination higher than acceptable by the regulations. This method permits eliminate the influence of false measurements coming from signals affected by high buildings and hills. This method is more reliable than commonly used digital filtering, which only waken this influence. The driver style of driving was subordinated to the style of driving randomly selected vehicle [12]. Selected vehicle was "followed" by test vehicle to prevent the influence of individual driving style of testing driver on test results.

In the Fig. 2 evaluated data set has been presented. The results has been calculated using equations (1) and (8), each point corresponds to real world traffic operating condition registered in city traffic or on the suburban ways (highest speed). Covered distances are not equal for each point and range form 2 up to $18 \mathrm{~km}$. It can be observed that lower average speed corresponds to higher share of the regenerative braking specific energy (71\%), which comes from typical city center traffic conditions - high number of stops and braking phases. It can be also seen for those conditions that there is a relatively large spread of points for the same speed $(32-64 \%)$. For the city center traffic conditions the same average speed can result from high maximum speed and long idling, as well as from almost constant low cruising speed. For higher average speed it can be observed stabilization of the share of the regenerative braking specific energy at the level of $8 \%$, which can be explain by the lack of traffic congestion on suburban ways and low number of braking phases.

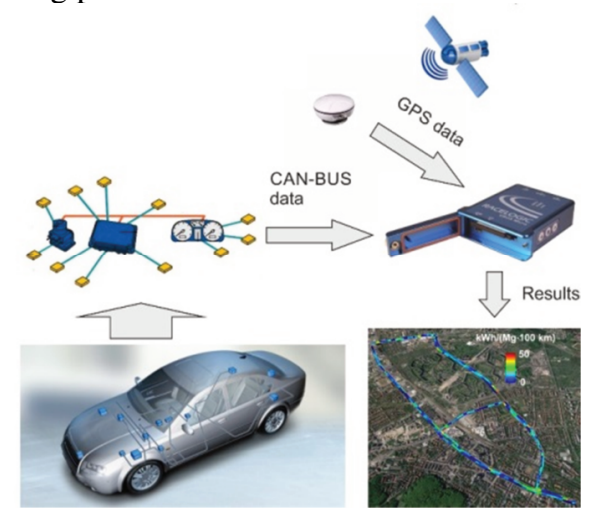

Fig. 1. System used for measurement of car and engine operating parameters 


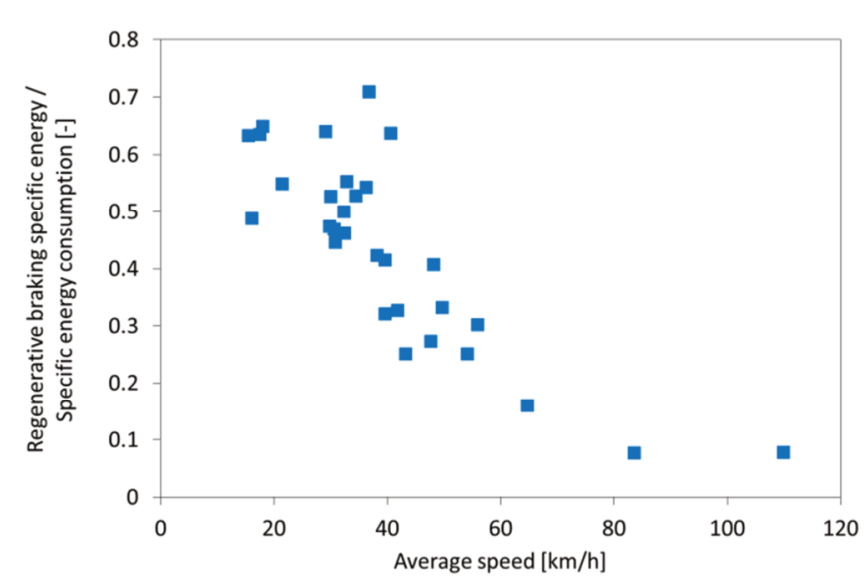

Fig. 2. Traffic conditions registered in urban and suburban area

The share of the regenerative braking specific energy can be evaluated for selected mean operating parameters using speed pattern presented in Fig. 3. It has been assumed that the vehicle movement can be divided into three phases: acceleration, constant speed (cruising) and braking (deceleration).

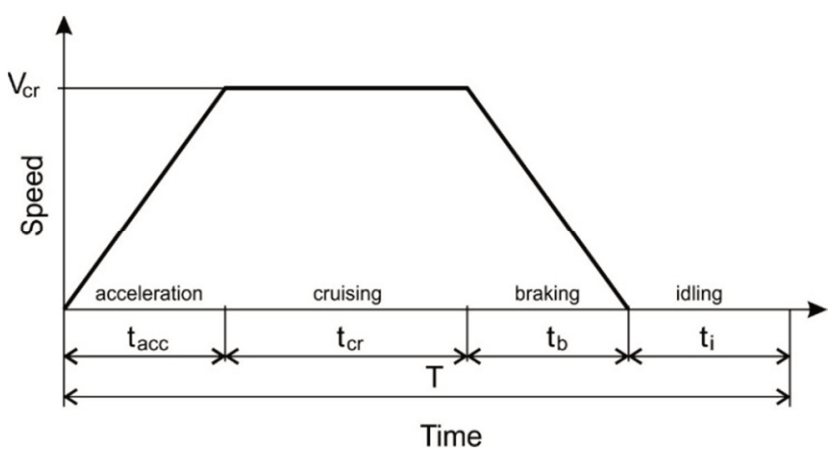

Fig. 3. The speed pattern used for evaluation of the share of the regenerative braking specific energy

Omitting influence of the road gradient the following relation can be made:

$$
\frac{\mathrm{RBSE}}{\mathrm{SEC}}=\frac{\left(\frac{\mathrm{m} \cdot \mathrm{V}_{\mathrm{cr}}^{2}}{2}-\mathrm{f}_{\mathrm{t}} \cdot \mathrm{m} \cdot \mathrm{g} \cdot \mathrm{L}_{\mathrm{b}}\right) /(\mathrm{m} \cdot \mathrm{L})}{\left(\frac{\mathrm{m} \cdot \mathrm{V}_{\mathrm{cr}}^{2}}{2}+\mathrm{f}_{\mathrm{t}} \cdot \mathrm{m} \cdot \mathrm{g} \cdot \mathrm{L}_{\mathrm{p}}\right) /(\mathrm{m} \cdot \mathrm{L})}
$$

where: $V_{c r}-$ the cruising speed between acceleration and braking, $f_{t}-$ the rolling resistance coefficient, $g-$ the gravitational constant, $\mathrm{L}_{\mathrm{b}}-$ the braking distance, $\mathrm{L}_{\mathrm{p}}-$ the powered distance.

Hence:

$$
\begin{gathered}
\frac{\mathrm{RBSE}}{\mathrm{SEC}}=\frac{1-2 \cdot \mathrm{f}_{\mathrm{t}} \cdot \mathrm{g} \cdot \frac{\mathrm{L}_{\mathrm{b}}}{\mathrm{V}_{\mathrm{cr}}^{2}}}{1+2 \cdot \mathrm{f}_{\mathrm{t}} \cdot \mathrm{g} \cdot \frac{\mathrm{L}_{\mathrm{p}}}{\mathrm{V}_{\mathrm{cr}}^{2}}} \\
\frac{\mathrm{RBSE}}{\mathrm{SEC}}=1-\frac{2 \cdot \mathrm{f}_{\mathrm{t}} \cdot \mathrm{g} \cdot\left[\frac{\mathrm{L}_{\mathrm{b}}}{\mathrm{L}}+\frac{\mathrm{L}_{\mathrm{p}}}{\mathrm{L}}\right] /\left(\frac{\mathrm{V}_{\mathrm{cr}}^{2}}{\mathrm{~L}}\right)}{1+2 \cdot \mathrm{f}_{\mathrm{t}} \cdot \mathrm{g} \cdot\left[\frac{\mathrm{L}_{\mathrm{p}}}{\mathrm{L}}\right] /\left(\frac{\mathrm{V}_{\mathrm{cr}}^{2}}{\mathrm{~L}}\right)}
\end{gathered}
$$

where:

$$
\left[\frac{\mathrm{L}_{\mathrm{b}}}{\mathrm{L}}+\frac{\mathrm{L}_{\mathrm{p}}}{\mathrm{L}}\right]=1
$$

then equation (13) reduces as:

$$
\frac{\mathrm{RBSE}}{\mathrm{SEC}}=1-\frac{1}{\frac{1}{2 \cdot \mathrm{f}_{\mathrm{t}} \cdot \mathrm{g} /\left(\frac{\mathrm{V}_{\mathrm{cr}}^{2}}{\mathrm{~L}}\right)}+\left[\frac{\mathrm{L}_{\mathrm{p}}}{\mathrm{L}}\right]}
$$

Because for the real traffic conditions the cruising speed can not be easy evaluated it has been assumed that there can be formulated relation between this parameter and average speed for the covered distance using pattern presented in Fig. 3:

$$
\mathrm{V}_{\mathrm{av}}=\left[\frac{1}{2} \cdot \mathrm{V}_{\mathrm{cr}} \cdot \mathrm{t}_{\mathrm{acc}}+\mathrm{V}_{\mathrm{cr}} \cdot \mathrm{t}_{\mathrm{cr}}+\frac{1}{2} \cdot \mathrm{V}_{\mathrm{cr}} \cdot \mathrm{t}_{\mathrm{b}}\right] \cdot \frac{1}{\mathrm{~T}}
$$

where: $V_{a v}$ - the average speed of analyzed cycle, $t_{a c c}-$ the acceleration phase time, $t_{b}-$ the braking phase time, $\mathrm{T}-$ the analyzed cycle time.

Taking into account that it is much easier for real traffic condition to define braking then accelerating phase, it has been assumed that $t_{a c c}=t_{b}$ and the relation (15) can be simplified:

$$
V_{a v}=V_{c r} \cdot\left[\frac{t_{a c c}}{T}+\frac{t_{c r}}{T}\right]=V_{c r} \cdot \frac{T-\left(t_{b}+t_{i}\right)}{T}
$$

where: $t_{i}-$ the idling time, hence:

$$
\mathrm{V}_{\mathrm{cr}}=\mathrm{V}_{\mathrm{av}} \cdot \frac{1}{1-\left(\mathrm{t}_{\mathrm{b}}+\mathrm{t}_{\mathrm{i}}\right) / \mathrm{T}}
$$

Finally the relation (14) can be transformed to the equation, which uses relatively easy to evaluate mean cycle parameters:

$$
\frac{\text { RBSE }}{\mathrm{SEC}}=1-\frac{1}{\frac{1}{2 \cdot \mathrm{f}_{\mathrm{t}} \cdot \mathrm{g}} \cdot\left(\frac{\mathrm{V}_{\mathrm{av}}^{2}}{\mathrm{~L}}\right) \cdot\left(\frac{1}{1-\frac{\left(\mathrm{t}_{\mathrm{b}}+\mathrm{t}_{\mathrm{i}}\right)}{\mathrm{T}}}\right)^{2}+\left[\frac{\mathrm{L}_{\mathrm{p}}}{\mathrm{L}}\right]}
$$

Using equation (18) the real traffic data has been compared to the calculation results (Fig. 4). It can be observed that the correlation between those data is not very good $\left(\mathrm{R}^{2}=0.7011\right)$. Hence, a few intuitively established relations have been additionally tested below.

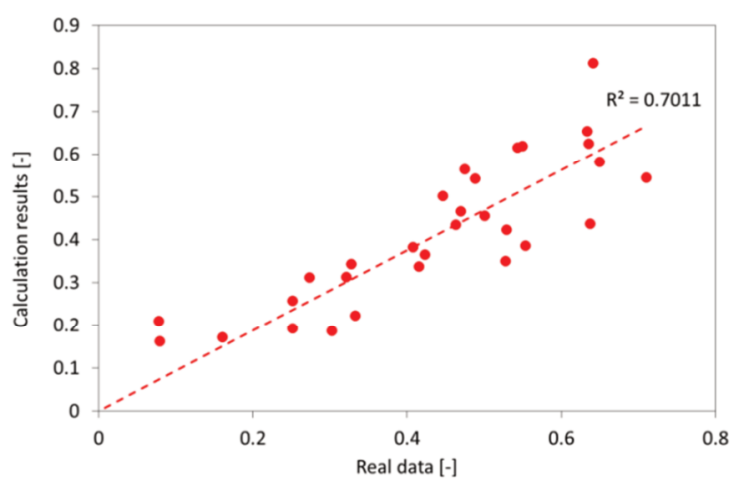

Fig. 4. Result of calculation of the of the share of the regenerative braking specific energy using equation (18) vs. the real traffic data 
It can be expected that higher share of the braking distance results in higher share the regenerative braking specific energy. The share of the braking distance for the real traffic data can be calculated using following relation:

$$
\frac{\mathrm{L}_{\mathrm{b}}}{\mathrm{L}}=\frac{1}{\mathrm{~L}} \cdot \sum_{\mathrm{i}=1}^{\mathrm{N}}\left(-\mathrm{k}_{\mathrm{reg}_{\mathrm{i}}} \cdot \mathrm{L}_{\mathrm{i}}\right)
$$

where: $\mathrm{L}_{\mathrm{b}} / \mathrm{L}$ - the braking distance share,

$$
\mathrm{L}=\sum_{\mathrm{i}=1}^{\mathrm{N}}\left(\mathrm{L}_{\mathrm{i}}\right)
$$

$\mathrm{k}_{\mathrm{reg}}$ - the negative traction force factor defined in equation (7), or it can be defined using powered distance share:

$$
\frac{\mathrm{L}_{\mathrm{b}}}{\mathrm{L}}=1-\frac{\mathrm{L}_{\mathrm{p}}}{\mathrm{L}}=1-\frac{1}{\mathrm{~L}} \cdot \sum_{\mathrm{i}=1}^{\mathrm{N}}\left(\mathrm{k}_{\mathrm{p}_{\mathrm{i}}} \cdot \mathrm{L}_{\mathrm{i}}\right)
$$

where: $\mathrm{L}_{\mathrm{p}} / \mathrm{L}$ - the powered distance share, $\mathrm{k}_{\mathrm{p}}$ - the positive traction force factor defined in equation (3).

It can be observed (Fig. 5) that there is good correlation between braking distance share and the regenerative braking distance share, hence, the general tendency can be confirmed in the following form:

$$
\frac{\mathrm{RBSE}}{\mathrm{SEC}}=\mathrm{a}_{1} \cdot \frac{\mathrm{L}_{\mathrm{b}}}{\mathrm{L}}+\mathrm{a}_{0}
$$

where: $a_{1}, a_{2}-$ the function coefficients.

However, there is a relatively large spread of points for the higher braking distance share, which suggests that some additional variables affect the share of the regenerative braking specific energy.

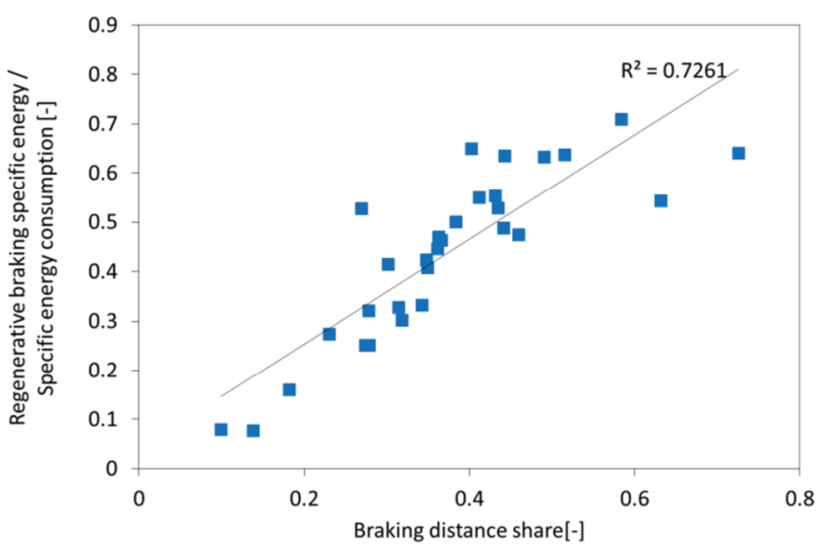

Fig. 5. Relation between the braking distance share and the share of the regenerative braking specific energy

Another two tested relations including: the idling time share and the specific energy consumption have not brought positive results. The idling time share can be defined using following equation:

$$
\frac{t_{i}}{T}=\frac{1}{T} \cdot \sum_{j=1}^{N}\left(t_{i_{j}}\right)
$$

It can be observed that for low values of the idling time share there is large spread of points (Fig. 6) but for higher values concentration of points is much higher, which suggests usage of this relation for limited range.
Using real world data it can be observed that the specific energy consumption and the share of the regenerative braking specific energy are uncorrelated variables (Fig. 7).

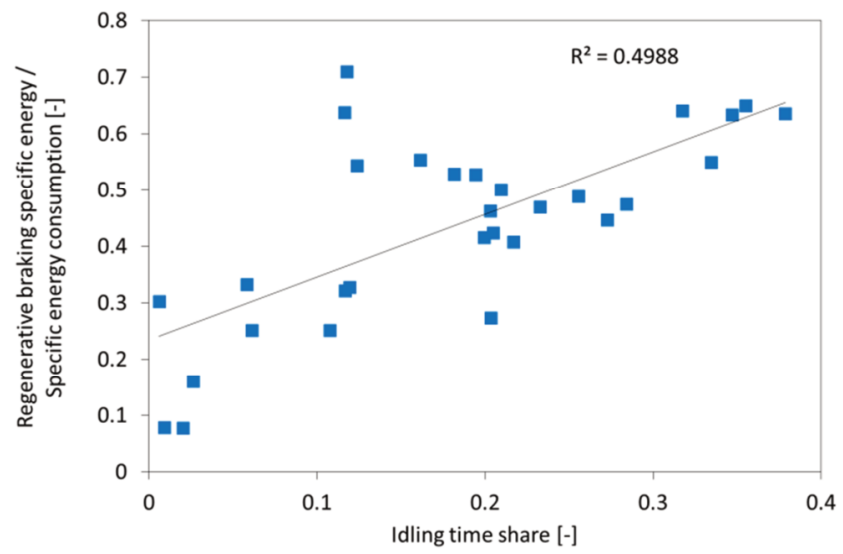

Fig. 6. Relation between the idling time share and the share of the regenerative braking specific energy

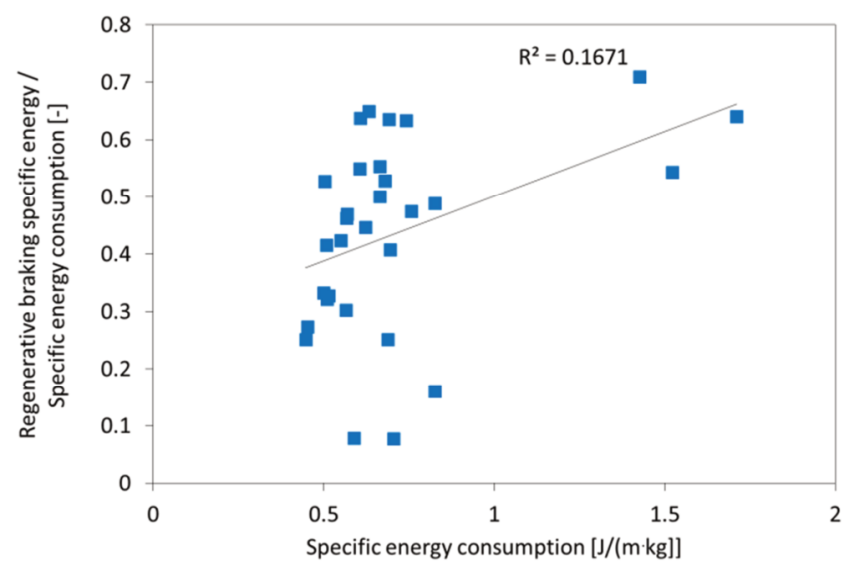

Fig. 7. Relation between the specific energy consumption and the share of the regenerative braking specific energy

\section{Conclusions}

This work contains an analysis of the process of the regenerative braking for the urban traffic conditions registered in Gdańsk. Information about the achievable regenerative braking energy for selected route should be use, when planning the route of hybrid and electric vehicles. It is expected that this functionality should be implemented in mobile car navigation systems, because continuous updating is necessary to maintain high system efficiency. Observation made in in real traffic in Gdańsk showed that low average speed corresponds to the highest share of the regenerative braking specific energy (71\%), which comes from typical city center traffic conditions - high number of stops and braking phases.

Presented in this work analyze of the regenerative braking process has been evaluated for the assumed simple speed pattern. Obtained model (18) enables calculation of the share the regenerative braking specific energy using relatively easy to evaluate mean cycle parameters, which is crucial for storing data from real world traffic. Using the model the real traffic data has been compared to the calculation results. It turned out that the correlation between 
those data is not very good $\left(\mathrm{R}^{2}=0.7011\right)$. Hence, a few intuitively established relations have been additionally tested. The best results have been achieved for tested relation: the braking distance share - the share of the regenerative braking specific energy. Evaluated linear relation (21) gives even better results then phenomenologically evaluated relation (18). Analyzing all tested relations it can be concluded that the share the regenerative braking specific energy is mainly affected by the braking distance share. The influence of other analyzed variables is changing depending on the range of the tested set. That implies, the relation describing the regenerative braking process should be represented by set of equations specific for pointed range of input variables.

\section{Bibliography}

[1] BIRRELL, S., et al. Analysis of three independent realworld driving studies: A data driven and expert analysis approach to determining parameters affecting fuel economy. Transportation Research Part D. 2014, 33, 74-86.

[2] CIEŚLIK, W., PIELECHA, I., SZAŁEK, A. Indexes of performance of combustion engines in hybrid vehicles during the UDC test. Combustion Engines. 2015, 160, 11-25.

[3] DAMIANI, L. et al. Improvement of powertrain efficiency through energy breakdown analysis. Applied Energy. 2014 121, 252-263.

[4] EEA Annual European Union greenhouse gas inventory 1990-2014 and inventory report 2016. Copenhagen 2016.

[5] FIORI, C. et al. Power-based electric vehicle energy consumption model: Model development and validation. Applied Energy. 2016, 168, 257-268.

[6] Goole Maps, https://www.google.com/maps (visited: 28.04.2019).

[7] JEFFREYS, I. et al. Evaluation of eco-driving training for vehicle fuel use and emission reduction: A case study in Australia. Transportation Research Part D. 2018, 60, 85-91.

[8] KALOCIŃSKI, T., RYMANIAK, Ł., FUĆ, P. Powertrain technology transfer between $\mathrm{F} 1$ and the Automotive industry based on Mercedes-Benz. Combustion Engines. 2018, 172, 3-13.

[9] KROPIWNICKI, J., KNEBA, Z., ZIÓŁKOWSKI, M. Test for assessing the energy efficiency of vehicles with internal combustion engines. International Journal of Automotive Technology. 2013, 14, 479-487.

[10] KROPIWNICKI, J., KNEBA, Z. Phenomenological correction of height above ground level of vehicle derived from GPS system. 6th International Conference Mechatronic Systems and Materials. 2010, 1-7.

Jacek Kropiwnicki, DSc., DEng. - Faculty of Mechanical Engineering, Gdańsk University of Technology.

e-mail: jkropiwn@pg.edu.pl
[11] KROPIWNICKI, J. Identification of real vehicle operating conditions with using of specific energy consumption. The Archives of Automotive Engineering. 2010, 3, 153-166.

[12] KULKARNI, A.V., SAPRE, R.R., SONCHAL, CH.P. GPSbased methodology for drive cycle determination. $S A E$ Technical Paper 2005-01-1060, 2005.

[13] MERSKY, A.C., SAMARAS, C. Fuel economy testing of autonomous vehicles. Transportation Research Part C. 2016, 65, 31-48.

[14] PIELECHA, I., CIEŚLIK, W., FLUDER, K. Analysis of energy management strategies for hybrid electric vehicles in urban driving conditions. Combustion Engines. 2018, 173, 14-18.

[15] PIELECHA, I., CIEŚLIK, W., SZAŁEK, A. The use of electric drive in urban driving conditions using a hydrogen powered vehicle -Toyota Mirai. Combustion Engines. 2018, 172, 51-58.

[16] STĘPIEŃ, Z. A new generation of F1 race engines - hybrid power units. Combustion Engines. 2016, 167, 22-37.

[17] TRIANTAFYLLOPOULOS, G. et al. Experimental assessment of the potential to decrease diesel $\mathrm{NO}_{\mathrm{x}}$ emissions beyond minimum requirements for Euro 6 Real Drive Emissions (RDE) compliance. Science of the Total Environment. 2018, 618, 1400-1407.

[18] Yanosik, https://yanosik.pl (visited: 28.04.2019).

[19] ZAHABI, S.A.H. et al. Fuel economy of hybrid-electric versus conventional gasoline vehicles in real-world conditions: A case study of cold cities in Quebec, Canada. Transportation Research Part D. 2014, 32, 184-192.

[20] ZHANG, R., YAO, E. Electric vehicles' energy consumption estimation with real driving condition data. Transportation Research Part D. 2015, 41, 177-187.

Mariusz Furmanek, MEng. - Faculty of Mechanical Engineering, Gdańsk University of Technology. e-mail:mfurmanek1@gmail.com
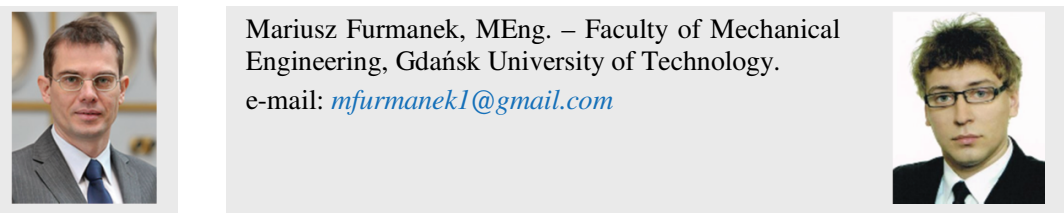